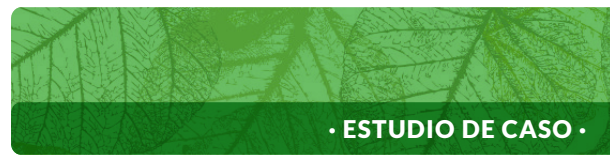

\title{
Análisis de peligros y puntos críticos de control en la elaboración de manjar blanco en una planta de derivados lácteos del municipio de Popayán*
}

\section{Hazard analysis and critical control points in the manufacturing of blancmange in a dairy derivatives plant in the municipality of Popayán}

\author{
ORTIZ-MUÑOZ, LINA-GABRIELA; ORTEGA-BONILLA, RUBÉN-ANDRÉS; \\ CHITO-TRUJILLO, DIANA-MARÍA ${ }^{3 *}$; RAMÍREZ-SANABRIA, ALFONSO-ENRIQUE4; \\ RADA-MENDOZA, MAITE-DEL PILAR ${ }^{5}$
}

Historial del Artículo

Recibido para evaluación: 29 de Abril 2020.

Aprobado para publicación: 16 de Noviembre 2020.

* Título del proyecto de orígen: “Optimización de los procesos de elaboración, calidad, trazabilidad y conservación del dulce de manjar blanco en la empresa Productos Alimenticios Rinconcito". Financiación: InnovAcción Cauca. Culminación: septiembre 6 de 2019.

1 Universidad del Cauca, Semillero Indicadores de Calidad, Grupo de Investigación Biotecnología, Calidad Medioambiental y Seguridad Agroalimentaria (BICAMSA). Química. Popayán, Colombia. https://orcid.org/0000-0002-9759-2844

2 Universidad del Cauca, Semillero Indicadores de Calidad, Grupo de Investigación Biotecnología, Calidad Medioambiental y Seguridad Agroalimentaria (BICAMSA). Magister en Sistemas de Producción Agroalimentaria. Popayán, Colombia. https:// orcid.org/0000-0002-2205-1349

3 Universidad del Cauca, Departamento de Química, Grupo de Investigación Biotecnología, Calidad Medioambiental y Seguridad Agroalimentaria (BICAMSA). Doctora en Ciencias. Popayán, Colombia. https://orcid.org/0000-0003-2163-6561

4 Universidad del Cauca, Departamento de Química, Grupo de Investigación Catálisis. Doctor en Química Aplicada. Popayán, Colombia. https://orcid.org/https://orcid.org/0000-0002-7557-4047

5 Universidad del Cauca, Departamento de Química, Grupo de Investigación Biotecnología, Calidad Medioambiental y Seguridad Agroalimentaria (BICAMSA). Ph.D. Ciencia y Tecnología Alimentos. Popayán, Colombia. https://orcid.org/0000-0003-1456-1653 


\section{RESUMEN}

El manjar blanco es un derivado lácteo comúnmente consumido en Latinoamérica. En Colombia, gran parte de su producción es artesanal y la realizan pequeñas y medianas empresas (PYMES). Los estándares de calidad del procesamiento del manjar blanco en estas PYMES se pueden mejorar a través del Análisis de Peligros y Puntos Críticos de Control-APPCC (o HACCP por sus siglas en inglés). En este estudio, se diseñó un plan de APPCC para el proceso de elaboración del manjar blanco en una empresa de derivados lácteos de la ciudad de Popayán (Cauca). Inicialmente, se valoró el perfil sanitario de la Empresa detectando un $70 \%$ de cumplimiento. Luego, se realizó un estudio descriptivo aplicando los siete principios del APPCC; los peligros se identificaron para las materias primas e insumos y para el proceso. El plan propuesto contiene: la descripción del producto y su uso, el diagrama de flujo del proceso, el análisis de peligros, la tabla de monitoreo del plan con los puntos críticos de control (PCC), medidas preventivas y el establecimiento de procedimientos de documentación y verificación. Las etapas del procesamiento que se identificaron como PCC fueron recepción de leche fresca, concentración final, dosificación, enfriamiento, sellado y etiquetado, y almacenamiento. La incidencia de los peligros químicos y biológicos identificados sobre la inocuidad del producto se debe verificar experimentalmente.

\section{ABSTRACT}

Blancmange is a dairy product commonly consumed in Latin America. In Colombia, a large part of its production is artisanal and is carried out by small and medium-sized enterprises (SMEs). The quality standards of manjar blanco processing in these SMEs can be improved through Hazard Analysis and Critical Control Points (or HACCP). In this study, a HACCP plan for the manufacturing process of manjar blanco in a dairy products company in Popayán (Cauca). Initially, the sanitary profile of the company was assayed, detecting $70 \% \mathrm{com}$ pliance. Then, a descriptive study was carried out by application of the seven principles of HACCP; hazards were identified for raw materials and supplies and for the process. The proposed plan contains: description of the product and its use, flowchart of the process, hazard analysis, table of plan control with the critical control points (CCP), preventive actions and the establishment of documentation and verification procedures. Processing stages identified as PCC were fresh milk reception, final concentration, dosage, cooling, sealing \& labeling, and storage. The incidence of chemical and biological hazards identified on the safety of the product must be verified experimentally.

Cómo citar este artículo: ORTIZ-MUÑOZ, LINA-GABRIELA; ORTEGA-BONILLA, RUBÉN-ANDRÉS; CHITO-TRUJILLO, DIANA-MARÍA; RAMÍREZ-SANABRIA, ALFONSO-ENRIQUE; RADA-MENDOZA, MAITE-DEL PILAR. Análisis de peligros y puntos críticos de control en la elaboración de manjar blanco en una planta de derivados lácteos del municipio de Popayán. Biotecnología en el sector agropecuario y agroindustrial, v. 19, n. 2, 2021, p. 214-233. Doi: https://doi.org/10.18684/bsaa.v19. n2.2021.1507

\section{PALABRAS CLAVE:}

Dulce de leche; Inocuidad alimentaria; Buenas Prácticas de Fabricación; APPCC; Calidad; Trazabilidad; Producto lácteo; Procesamiento; Puntos críticos; Peligros.

\section{KEYWORDS:}

Milk jam; Food Safety; Good Manufacturing Practices; HACCP; Quality; Traceability; Milk product; Processing; Critical points; Hazards. 


\section{INTRODUCCIÓN}

En el mundo, cerca de 600 millones de personas se enferman cada año por ingerir alimentos contaminados. La contaminación de los alimentos se puede producir en cualquiera de las etapas del proceso de fabricación o de distribución, aunque la responsabilidad recae principalmente en el productor según la ORGANIZACIÓN MUNDIAL DE LA SALUD (OMS, 2019). Las empresas de alimentos, y con mayor afectación las microempresas, deciden asumir costos de la inocuidad como parte de su economía operativa para mantener su competitividad, los cuales podrían evitarse con procedimientos básicos de limpieza (Ortega and Hernández, 2017). Los sistemas de control, de higiene y calidad de los productos alimenticios, surgen con el objetivo de evitar la aparición de enfermedades causadas por alimentos y así poder afrontar con mayor competitividad, la globalización de los mercados. Este entorno exige, por lo tanto, un cambio en el control de los productos alimentarios, que implica pasar de los controles aleatorios tradicionales, a un sistema de autocontrol para el aseguramiento de la calidad del producto final, incluyendo todas las fases de la cadena agroalimentaria según el InSTITUTO ColombiAno De NormAs TÉCnICAS Y CERTIFICACIÓN INTERNACIONAL (ICONTEC Internacional, 2018). Es en este contexto, que surge en la década de los años cincuenta, el sistema de Análisis de Peligros y Puntos Críticos de Control (HACCP por sus siglas en inglés); éste es un método sistemático y preventivo, dirigido a la identificación, evaluación y control de los peligros asociados con las materias primas, ingredientes, procesos, comercialización y su uso por el consumidor, a fin de garantizar la inocuidad del producto alimenticio (Organismo Internacional Regional De Sanidad Agropecuaria, 2017). El término peligro se refiere a cualquier agente o condición de los alimentos que es inaceptable, debido a su potencial de causar un efecto adverso para la salud (Najah and Putri, 2019). Por su parte, un punto de control crítico es la etapa del proceso en el que se puede aplicar una medida de seguridad que previene, elimina o reduce los niveles inaceptables de peligro (Birhanu et al., 2017). Un diseño de plan APPCC constituye una herramienta oportuna para que los productores identifiquen los peligros y establezcan las medidas para su prevención y control, promuevan la comercialización de sus productos a través del cumplimiento de las normas y procedimientos de auditoría que verifiquen su correcto diseño y aplicación. Además, es un sistema ventajoso capaz de adaptarse a los cambios que supone para una instalación de procesamiento de alimentos la incorporación de innovaciones en procesos o tecnológicas (Comisión Del Codex Alimentarius, 1997; Kakimov et al., 2020).

La industria de productos lácteos y derivados a nivel mundial ha logrado la producción de alimentos seguros en los últimos años debido a la implementación de prácticas de almacenamiento y procesos térmicos de conservación, estrategias de comercialización y/o prácticas de penalización del precio de compra, entre otros. Sin embargo, la literatura reporta casos recientes con amenazas por microorganismos patógenos (van-Asselt et al., 2017; Cancino et al., 2017; Tomar and Akarca, 2019), y en Colombia particularmente, aun predomina la informalidad en el sector lácteo por lo que la implementación del sistema APPCC en empresas de este sector, clasificado como productor de alimentos de mayor riesgo en términos de salud pública según el Decreto 3075 (Ministerio De Salud De Colombia, 1997), representa una estrategia factible para minimizar los riesgos asociados a sus procesos de producción. En Colombia, hasta la fecha, la aplicación del sistema APPCC por las empresas y microempresas es voluntaria, no obstante, las exigencias del mercado y el fenómeno de globalización, promueven el interés por instaurar el sistema a uno o varios procedimientos productivos.

El manjar blanco hace parte de los productos tradicionales de los países de Latinoamérica y es conocido con nombres tales como dulce de leche, manjar de leche, arequipe o cajeta (Greco et al., 2017). La Norma Técnica Colombiana NTC 3757 (ICONTEC, 2008) lo define como un derivado lácteo obtenido por la concentración térmica de una mezcla de leche, sacarosa u otros edulcorantes y aditivos permitidos por la legislación nacional vigente, con el agregado de harina o almidones. Su producción y comercialización representa un pequeño sector dentro de los productos lácteos y la mayoría de los países que lo producen lo hacen para consumo interno de manera artesanal, siendo Argentina el país más representativo en la producción y posicionamiento en el mercado (Greco et al., 2017). La producción industrial está a cargo de empresas tradicionales y/o familiares (Novoa and Ramírez et al., 2012). Para las pequeñas empresas del suroccidente colombiano, el manjar blanco se constituye en un producto insignia y, a pesar de ser capaces de abastecer la demanda nacional durante todo el año, deben asumir una baja tasa de crecimiento, debido al considerable aumento en el número de devoluciones del producto, debido a 
la aparición antes de los 90 días de vida en anaquel, de mohos cuyas especies más extendidas son de los géneros Eurotium, Aspergillus y Penicillium (Greco et al., 2017; Garnier et al., 2017; Chen et al., 2017) y se asocian con la producción de micotoxinas o compuestos tóxicos producidos por estos de forma natural (Ferrão et al., 2017; Ruíz et al. 2017). La inocuidad del manjar blanco depende principalmente, de la calidad y de las condiciones de recepción de la leche cruda, del comportamiento del inóculo, de la contaminación que pueda adquirir durante el proceso de elaboración debido a equipos u operarios y de las condiciones de almacenamiento.

Para la elaboración del diseño del plan APPCC en la empresa de derivados lácteos, se seleccionó el manjar blanco, puesto que es el producto premium desde hace casi 30 años y a que es consumido por un alto porcentaje de la población a nivel nacional (Ramírez et al., 2015), de diferentes edades, dado que su comercialización incluye programas de alimentación escolar y población vulnerable. Este trabajo tuvo por objetivo realizar el diseño del Plan APPCC de la línea de producción de manjar blanco desarrollada en una empresa del Departamento del Cauca, que promueva su implementación a corto plazo, favorezca sus niveles de productividad con calidad y de confianza a los comercializadores y consumidores, y motive a otros productores de la región a replicarlo.

\section{MÉTODO}

\section{Lugar de estudio}

En este estudio se monitoreó el proceso de elaboración de manjar blanco que se lleva a cabo en una planta de derivados lácteos del municipio de Popayán, departamento del Cauca (Colombia) ubicada en el kilómetro 14 autopista panamericana vía Popayán-Cali $\left(2^{\circ} 35^{\prime} \mathrm{N} 76^{\circ} 32^{\prime} \mathrm{W}\right)$ con valores de temperatura en el rango de 18 a 33,4 ${ }^{\circ} \mathrm{C}$, y de humedad relativa entre 33,2 y $82,80 \%$ según los registros diarios obtenidos con termohigrómetros (MA-LINE MA16542) dispuestos en las diferentes zonas de la planta de proceso en junio de 2018. Para el diseño del plan APPCC se conformó el Equipo APPCC, integrado por el jefe de producción de la planta, el supervisor de calidad y mantenimiento, con el acompañamiento de los investigadores del proyecto, quienes soportaron las actividades de diseño.

\section{Prerrequisitos}

La empresa contaba con certificación del Instituto Nacional de Vigilancia de Medicamentos y Alimentos (INVIMA) por el cumplimiento de Buenas Prácticas de Manufactura (BPM), sin embargo, previo al análisis de peligros se realizaron visitas a la planta de procesamiento para la verificación del sistema de calidad, de acuerdo con los requerimientos exigidos por el Decreto 3075 (Ministerio De Salud De Colombia, 1997) y utilizando el formato sugerido por el INVIMA. Previo al análisis de peligros se valoraron las materias primas e insumos requeridos para la fabricación del manjar blanco y se evaluó el tipo de peligros asociados.

\section{Plan HACCP}

El equipo APPCC aplicó los siete principios establecidos por la Comisión Del Codex Alimentarius (1997): (1) Realizar un análisis de peligros, (2) Identificar los Puntos críticos de control (PCC), (3) Establecer límites críticos para las medidas preventivas asociadas con cada PCC identificado, (4) Establecer requisitos de monitoreo de PCC, (5) Establecer las acciones correctivas a adoptar cuando el monitoreo evidencia una desviación de un límite crítico establecido. (6) Establecer procedimientos de verificación y, (7) Establecer los procedimientos de mantenimiento de registros y documentación.

A través de visitas de campo a la planta se construyó el diagrama de flujo del proceso que se esquematiza en dos fases en la figura 1. La fase 1 comprendió las etapas de recepción de las materias primas y neutralización de la leche y la segunda fase la etapa de concentración, enfriamiento, dosificación, envasado y almacenamiento en planta. En detalle, el personal recepcionó las materias primas (leche cruda, azúcar, glucosa, bicarbonato de sodio, citrato de 
sodio, fécula de maíz y sorbato de potasio) y monitoreó los niveles de acidez, densidad y temperatura de la leche. Luego, la leche se transfirió a las marmitas de 240 L de capacidad y se inició el proceso de neutralización sin alteración de sabor con la adición de bicarbonato de sodio requerido para evitar la coagulación de la caseína por la concentración de ácido láctico, el descenso del pH por debajo de 4,7 y el favorecimiento de las reacción de Maillard durante la etapa de concentración (Stephani et al., 2019; Hiroshi et al., 2020); en esta misma etapa se procedió a definir la formulación del producto con la adición de sacarosa y citrato de sodio que actúa como estabilizante (Novoa and Ramírez, 2012). Cuando la mezcla alcanzó su temperatura de ebullición, se trasladó a recipientes plásticos (polietileno de ultra peso molecular, PUPM), de capacidad similar a las marmitas. Seguido, se complementó la formulación con la adición de fécula, se monitoreó el nivel de ${ }^{\circ}$ Brix y se limpiaron profundamente las marmitas.

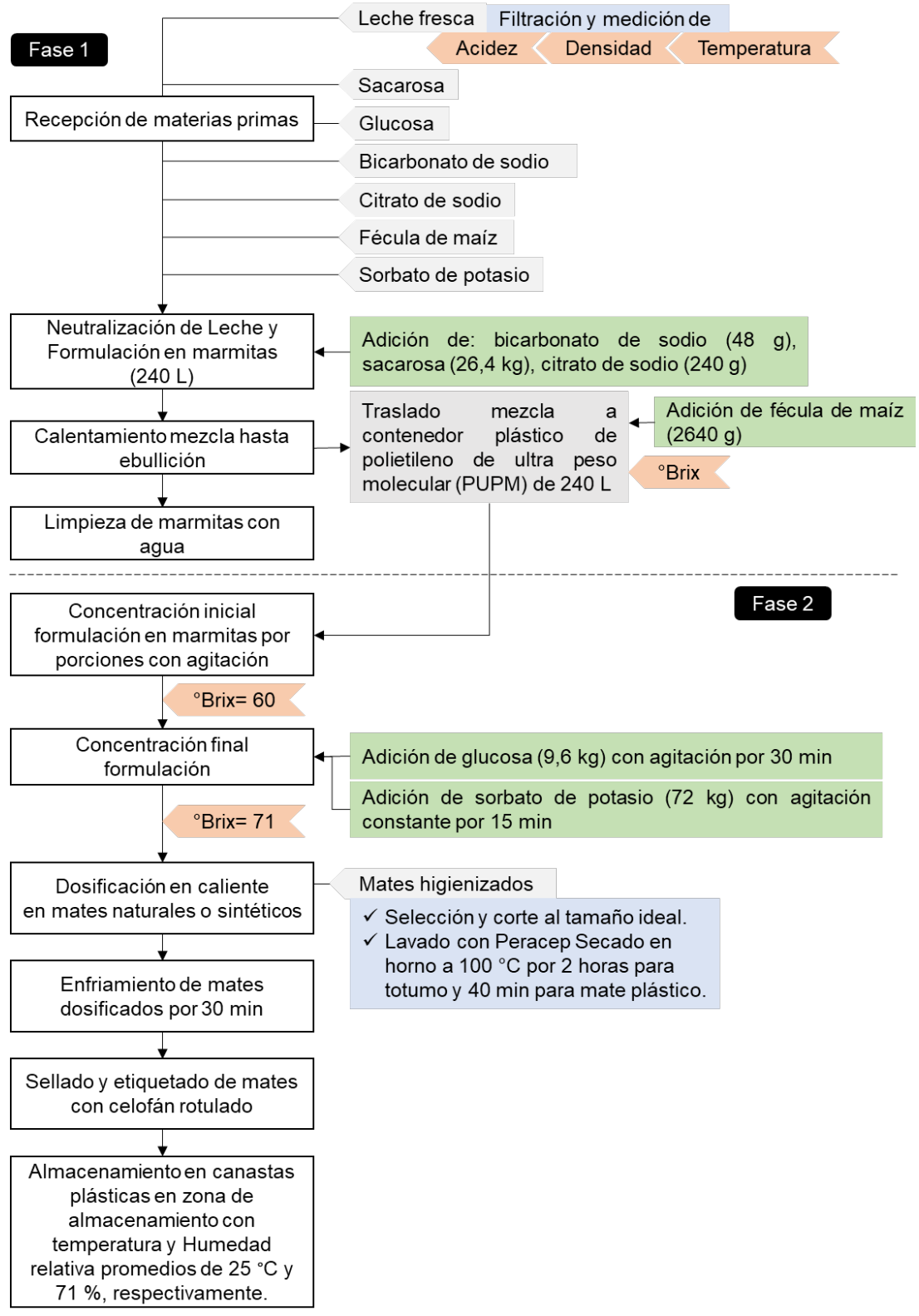

Figura 1. Diagrama de flujo del proceso de elaboración de manjar blanco. 
Posteriormente, tuvo lugar la fase 2 en la que la mezcla se transfirió a las marmitas de forma porcionada, con el fin de disminuir el tiempo de concentración. Este proceso sucedió en un tiempo aproximado de 2,5 horas o hasta que la mezcla registró $60^{\circ}$ Brix. En esta etapa se adicionó la glucosa para disminuir la solubilidad de la sacarosa, regular el dulzor y posibilitar un pardeamiento no enzimático (Rodríguez et al., 2019) y se mantuvo el calentamiento por 30 minutos. Así mismo, se adicionó el conservante, sorbato de potasio (ICONTEC, 2008), manteniendo agitación por 15 minutos más. En este punto, se verificó en el producto un valor de $71^{\circ}$ Brix o un nivel de concentración deseado, y se procedió a dosificar el producto en mates de totumo o de plástico ajustados al volumen deseado e higienizados. Una vez se terminó la dosificación (por 30 min), el mate se selló, se etiquetó y se almacenó en la zona de la planta destinada para ello.

El diagrama de flujo se empleó como guía para identificar todos los potenciales peligros biológicos, químicos y físicos en cada etapa y se estimó si la incidencia del peligro era o no significativa para la inocuidad del alimento, siguiendo la metodología del árbol de decisiones propuesta por el Codex Alimentarius (1997). Posteriormente, se determinaron los límites de control en función de las bases científicas del proceso y del conocimiento del nivel de riesgo de los peligros, y se documentó la información del Reporte de Análisis de Peligros.

El sistema de monitoreo se diseñó para garantizar el cumplimiento de los límites críticos de Control para cada PCC. Se definieron las frecuencias y procedimientos de medición y los responsables del monitoreo. El equipo APPCC identificó para cada uno de los PCC las acciones correctivas a seguir en caso de evidenciar desviaciones. Finalmente se establecieron los procedimientos de verificación del sistema APPCC (revisión de todo el sistema y sus registros).

\section{RESULTADOS}

Los porcentajes de cumplimiento total y detallado para cada aspecto se muestran en la figura 2. La empresa logró un cumplimiento de 70 \% de los requisitos y se identificó el aspecto denominado requisitos higiénicos de fabricación como el más deficiente, en tanto que el personal manipulador de alimentos como el mejor evaluado (92\%). Después de verificar los prerrequisitos se inició el diseño del plan APPCC del proceso de elaboración del manjar blanco de acuerdo con la metodología.

\section{Descripción del producto, uso y tipo de consumidor}

El manjar blanco se caracteriza por su color marrón, superficie lisa, brillante y sin crecimiento de mohos y textura cremosa. El dulce se comercializa en presentaciones de 40,125, 250 y $450 \mathrm{~g}$ en mates naturales o sintéticos sellados con un celofán. El producto en un empaque hermético y bajo una temperatura de $20^{\circ} \mathrm{C}$ presenta una vida útil de 90 días. Sus características fisicoquímicas principales son: grasa mínima 6,5\%, extracto seco mínimo $65 \%, y^{\circ}$ Brix $\geq 65$ (Novoa and Ramírez, 2012). Desde el punto de vista microbiológico, los recuentos de coliformes y mohos y levaduras deben estar entre 10 y 100 UFC/g, el de Staphylococcus aureus entre 10 y 200 UFC/g y el de Escherichia coli 10 UFC/g (ICONTEC, 2008).

Su consumo es tradicional en las reuniones y fiestas, aunque se intensifica en la época decembrina (Novoa and Ramírez, 2012) en personas de ambos géneros, todos los segmentos de edad ( $>1$ año, aunque se acentúa después de la adolescencia), diferentes ocupaciones (funcionarios, estudiantes, amas de casa, etc.), estratos socioeconómicos y procedencia geográfica (Ramírez et al., 2015; Restrepo et al., 2015). 


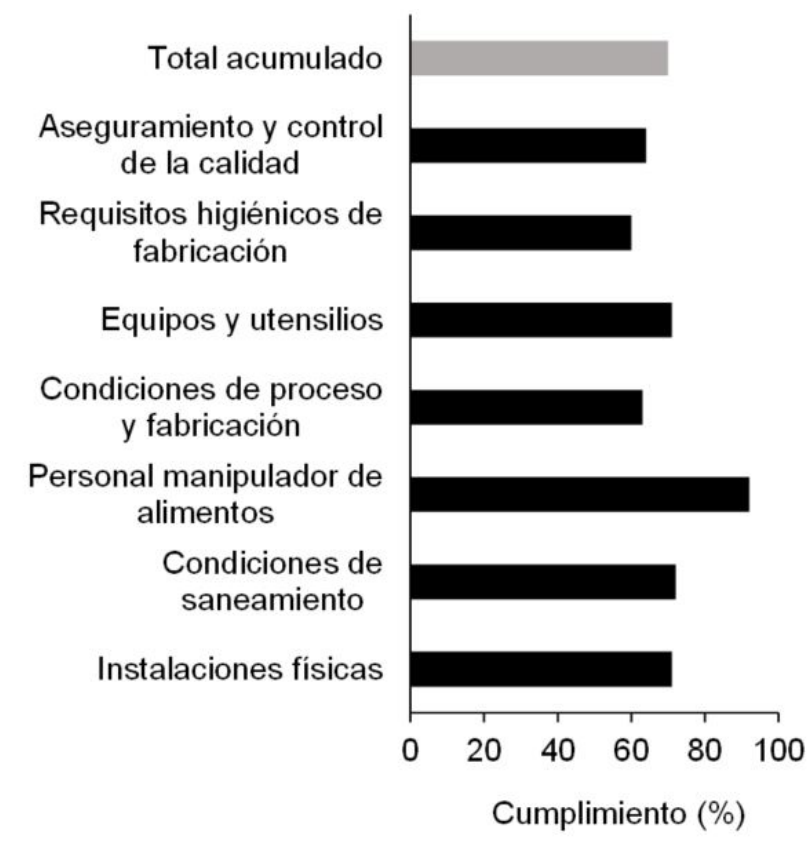

Figura 2. Porcentaje de cumplimiento de las BPM y POLD de la empresa según el Decreto 3075 de 1997 (Ministerio De Salud De Colombia, 2008).

\section{Análisis de Peligros}

La evaluación de los peligros potenciales y riesgos asociados de las materias primas e insumos empleados en la elaboración del manjar blanco, se presentan en el Cuadro 1. Sacarosa, glucosa, fécula de maíz, bicarbonato y citrato de sodio, sorbato de potasio, agua y mates (sintéticos y naturales) son materias primas e insumos que no se consideran PCC, dado que los proveedores cuentan con certificación en Sistemas de Gestión de Calidad ISO 9000, registro sanitario INVIMA, cumplen con la certificación ICONTEC de fabricación del producto y proporcionan fichas técnicas o certificado de análisis en el proceso de recepción.

Cuadro 1. Evaluación de materias primas e insumos usados en la elaboración del manjar blanco. Adaptado de van-Asselt (2017).

\begin{tabular}{|c|c|c|c|c|}
\hline MPol & Peligro potencial & $\begin{array}{c}\text { Antecedentes de calidad MP-I } \\
\text { y/o proveedor }\end{array}$ & $\begin{array}{l}\text { ¿Los peligros } \\
\text { de la MP o I se } \\
\text { eliminarán } \\
\text { por el proceso? }\end{array}$ & $\begin{array}{l}\text { MP o I se con- } \\
\text { sidera un PCC } \\
\text { (¿sí o no?) }\end{array}$ \\
\hline Sacarosa & $\begin{array}{l}\text { Físico: piedras } \\
\text { Químico: N/A } \\
\text { Biológico: mesófilos }\end{array}$ & $\begin{array}{l}\text { Registro sanitario INVIMA } \\
\text { Certificación ISO } 9000 \\
\text { NTC 778: Azúcar refinado } \\
\text { Entrega de fichas técnicas } \\
\text { Certificado de análisis }\end{array}$ & Sí & No \\
\hline Glucosa & $\begin{array}{l}\text { Físico: No } \\
\text { Químico: contaminado química- } \\
\text { mente } \\
\text { Biológico: mohos y levadura, gér- } \\
\text { menes aerobios }\end{array}$ & $\begin{array}{l}\text { Registro sanitario INVIMA } \\
\text { Entrega de fichas técnicas } \\
\text { Certificado de análisis } \\
\text { Cumplimiento de BPM }\end{array}$ & $\begin{array}{l}\text { Químico: No } \\
\text { Biológico: Sí }\end{array}$ & No \\
\hline $\begin{array}{l}\text { Bicarbonato } \\
\text { de sodio }\end{array}$ & $\begin{array}{l}\text { Físico: No } \\
\text { Químico: contaminado química- } \\
\text { mente } \\
\text { Biológico: No }\end{array}$ & $\begin{array}{l}\text { Registro sanitario INVIMA } \\
\text { Entrega de fichas técnicas } \\
\text { Certificado de análisis }\end{array}$ & $\begin{array}{l}\text { Químico: No } \\
\text { Biológico: Sí }\end{array}$ & No \\
\hline
\end{tabular}




\begin{tabular}{|c|c|c|c|c|}
\hline MPol & Peligro potencial & $\begin{array}{c}\text { Antecedentes de calidad MP-I } \\
\text { y/o proveedor }\end{array}$ & $\begin{array}{l}\text { ¿Los peligros } \\
\text { de la MP o I se } \\
\text { eliminarán } \\
\text { por el proceso? }\end{array}$ & $\begin{array}{l}\text { MP o I se con- } \\
\text { sidera un PCC } \\
\text { (¿sí o no?) }\end{array}$ \\
\hline $\begin{array}{l}\text { Citrato de } \\
\text { sodio }\end{array}$ & $\begin{array}{l}\text { Físico: No } \\
\text { Químico: contaminado química- } \\
\text { mente } \\
\text { Biológico: mohos y levaduras }\end{array}$ & $\begin{array}{l}\text { Registro sanitario INVIMA } \\
\text { Entrega de fichas técnicas } \\
\text { Certificado de análisis }\end{array}$ & $\begin{array}{l}\text { Químico: No } \\
\text { Biológico: Sí }\end{array}$ & No \\
\hline $\begin{array}{l}\text { Fécula de } \\
\text { maíz }\end{array}$ & $\begin{array}{l}\text { Físico: No } \\
\text { Químico: contaminado química- } \\
\text { mente, pesticidas } \\
\text { Biológico: mohos y levaduras }\end{array}$ & $\begin{array}{l}\text { Registro sanitario INVIMA } \\
\text { NTC 926: Productos de molinería. } \\
\text { Fécula de maíz. } \\
\text { Entrega de fichas técnicas } \\
\text { Certificado de análisis }\end{array}$ & $\begin{array}{l}\text { Químico: No } \\
\text { Biológico: Sí }\end{array}$ & No \\
\hline $\begin{array}{l}\text { Sorbato de } \\
\text { potasio }\end{array}$ & $\begin{array}{l}\text { Físico: No } \\
\text { Químico: contaminado química- } \\
\text { mente } \\
\text { Biológico: No }\end{array}$ & $\begin{array}{l}\text { Registro sanitario INVIMA } \\
\text { Entrega de fichas técnicas } \\
\text { Cumplimiento de BPM }\end{array}$ & $\begin{array}{l}\text { Químico: No } \\
\text { Biológico: Sí }\end{array}$ & No \\
\hline Leche fresca & $\begin{array}{l}\text { Físico: piedras, moscas, } \\
\text { otras partículas } \\
\text { Químico: antibióticos, metales } \\
\text { pesados, pesticidas, contaminación } \\
\text { con aceite durante transporte } \\
\text { Biológico: patógenos por enfria- } \\
\text { miento deficiente durante ordeño y } \\
\text { transporte hacia la planta, mesófi- } \\
\text { los, salmonella, E. coli, Listeria }\end{array}$ & - & $\begin{array}{l}\text { Físico: Sí } \\
\text { Químico: No } \\
\text { Biológico: Sí }\end{array}$ & No \\
\hline Agua & $\begin{array}{l}\text { Físico: color } \\
\text { Químico: metales pesados, pH, } \\
\text { turbidez. } \\
\text { Biológico: mesófilos, coliformes } \\
\text { totales, Pseudomonas aeruginosa }\end{array}$ & $\begin{array}{l}\text { Acueducto veredal constituido } \\
\text { Certificado de análisis }\end{array}$ & $\begin{array}{l}\text { Físico: No } \\
\text { Químico: No } \\
\text { Biológico: Sí }\end{array}$ & No \\
\hline Mates & $\begin{array}{l}\text { Físico: fisuras, polvillo } \\
\text { Químico: contaminado química- } \\
\text { mente } \\
\text { Biológico: microorganismos en el } \\
\text { ambiente }\end{array}$ & - & $\begin{array}{l}\text { Físico: Sí } \\
\text { Químico: Sí } \\
\text { Biológico: Sí }\end{array}$ & No \\
\hline
\end{tabular}

MP: materia prima. I: insumo.

Para estos casos, se identificaron peligros físicos, químicos y/o biológicos que se pueden eliminar durante el procesamiento del dulce por efecto de la temperatura que se alcanza durante la etapa de concentración, y algunos que con una medida de control y preventiva como el control de limpieza, filtración, limpieza de equipos y/o superficies, pruebas de plataforma y seguimiento del proveedor se pueden corregir y/o evitar, o por los niveles esperados en el producto no se constituyen en un PCC.

La leche fresca, por su obtención y manipulación, se convierte en una materia prima bastante susceptible de presentar peligros de naturaleza física, química y biológica. La planta procesadora del manjar blanco se abastece de esta materia prima a través de un proveedor (conocido como rutero) que la acopia desde los hatos lecheros de veinte productores (en promedio) del municipio de Totoró que es un sector productor de leche ubicado geográficamente cerca de la planta. Los productores de leche pueden o no tener conocimiento de la normativa técnica aplicable a su obtención y/o registro mercantil (Meneses et al., 2015), lo que promueve la distribución de un alimento con una calidad insuficiente y con diversos riesgos físicos, químicos y biológicos (Motta et al., 2014; Díaz et al., 2015; Birhanu et al., 2017). Entre los aspectos técnicos críticos en el eslabón de acopio y distribución de la leche se destacan: locaciones no aptas en los predios de producción, una incorrecta higienización, vehículos que no son especializados para su transporte, tiempo de almacenamiento en ausencia de refrigeración y en recipientes no aptos (por ejemplo, en pomas plásticas), limitaciones en la indumentaria que usan los ruteros (bata, gorro y tapabocas en buen estado y limpios) y en el uso del termómetro para verificar la temperatura de la 
leche que reciben y distribuyen, exigidos por la Secretaria de Salud del Cauca. Un estudio de caso del año 2015 (Meneses et al., 2015), reportó la caracterización de la cadena informal de la leche cruda en el municipio de Popayán, revelando que 51 de 60 procesadores encuestados en la capital del departamento del Cauca no cuentan con registro mercantil, y de estos, 36 se ubicaban en zonas rurales; el ordeño, en casi el $90 \%$ de los predios se realiza de forma manual, en potreros, patios de las casas y corrales en el $66 \%$ de las fincas, los recipientes empleados eran plásticos (55\% de los predios) o combinados con metálicos ( $22 \%$ de las fincas), pero sólo en el $31 \%$ se empleaba hipoclorito de sodio para su desinfección; un $86 \%$ de los predios entregaban la leche a temperatura ambiente, sin ninguna prueba de calidad y podía permanecer así hasta por 70 minutos antes de entregar al rutero. Así mismo, los autores identificaron que en más del $70 \%$ de los predios se aplicaban vacunas y usaban medicamentos, pero más de la mitad de ellos sin ningún tipo de seguimiento; a esto se suma la detección de enfermedades en las vacas, pero sin diagnóstico certero. Teniendo en cuenta lo anterior, la leche fresca que adquiere la empresa afectaría a la planta y ocasionaría un peligro significativo a la inocuidad del producto.

Los riesgos y peligros que se detectaron (Principio 1) durante el proceso de elaboración de dulce manjar blanco en la planta de producción, las medidas de control para cada peligro identificado y los PCC que se definieron (Principio 2) a partir de la aplicación del árbol de decisión (Najah and Prutri, 2019) se muestran en el Cuadro 2.

Para el caso de la valoración de la calidad higiénica de la leche en la etapa de recepción, la empresa podría aplicar la rutinaria prueba de la reductasa bacteriana, o adquirir equipos automatizados como BactoScan FC ${ }^{\circledR}$ y FossomaticMinorTM que ofrecen alta sensibilidad, rapidez y simplicidad (Remón et al., 2019). Peligros químicos como los que suponen las etapas de limpieza de las marmitas, concentración final y dosificación se deben corregir previo a la implementación del plan APPCC en pro del cumplimiento de los prerrequisitos contemplados en el perfil sanitario (requisitos higiénicos de fabricación, condiciones de proceso y fabricación, y aseguramiento y control de la calidad en figura 2, dado que son fallas higiénicas y el árbol de decisiones no los clasifica como PCC.

El análisis de peligros permitió identificar como PCC las etapas de recepción de leche fresca, concentración final, dosificación, enfriamiento, sellado y etiquetado y almacenamiento. El cuadro 3 muestra los PCC indicando los límites críticos (Principio 3), el sistema de vigilancia (Principio 4) y las medidas correctivas (Principio 5) cuando un PCC presenta una desviación de sus límites críticos, verificación (Principio 6) y registros (Principio 7).

La empresa no desarrolla actividades de seguimiento a los proveedores de leche fresca, ni a sus características fisicoquímicas y microbiológicas antes de la entrega o realiza suficientes mediciones en la etapa de recepción; estos hechos no permiten reducir los peligros potenciales de esta materia prima y evidencia la imperante necesidad de comprometer a los actores de la cadena láctea de la región, a implementar Buenas Prácticas Ganaderas y el sistema APPCC en sus procesos de obtención de leche fresca y refrigerada. Por ello, la etapa de recepción de la leche fresca para la elaboración del manjar blanco supone un punto crítico de control dado que los riesgos químicos (residuos de antibióticos, pesticidas y metales pesados derivados de un mal manejo técnico previo) y biológicos (microorganismos mesófilos a causa de su calidad y de la manipulación durante su obtención, transporte y recepción) asociados puede poner en riesgo la salud de los consumidores del producto al promover niveles biodisponibles perjudiciales para las membranas biológicas de los seres humanos (Díaz and Betancourt, 2018; Castro et al., 2019) y es necesario que esta etapa se controle para reducir su incidencia a niveles aceptables; además, la utilización de leche con calidad de leche regular o aceptable alteraría el rendimiento del producto en aproximadamente un $5 \%$ representando pérdidas económicas importantes para una microempresa. En esta etapa, el monitoreo de la acidez de la leche que realiza la empresa garantiza, además, el alcance de una textura homogénea en el producto (ausencia de grumos), un atributo determinante en la preferencia del consumidor según las impulsadoras del producto en plataformas comerciales y limita las devoluciones. 


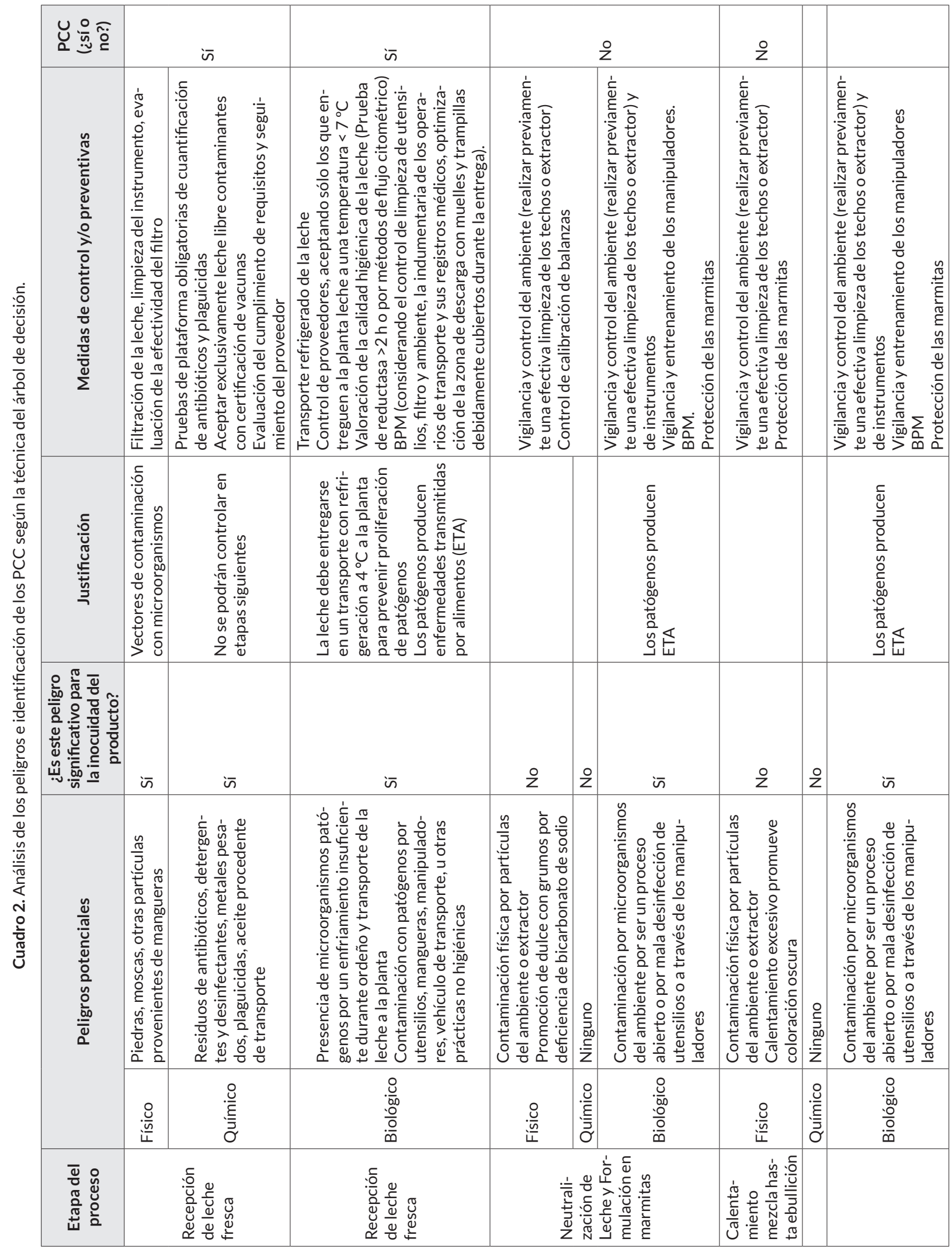




\begin{tabular}{|c|c|c|c|c|c|c|c|c|c|}
\hline 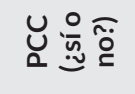 & \multicolumn{3}{|c|}{ zo } & \multicolumn{3}{|c|}{ ㅇ } & \multicolumn{3}{|c|}{$i n$} \\
\hline 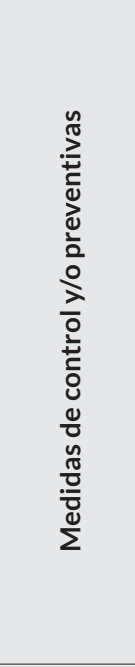 & 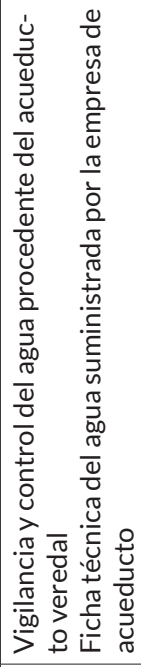 & 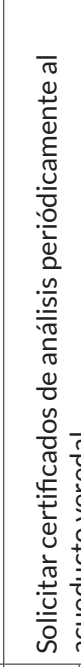 & 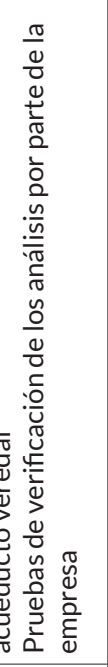 & 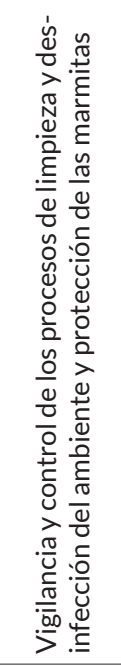 & & 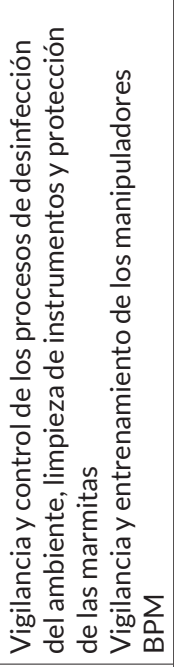 & 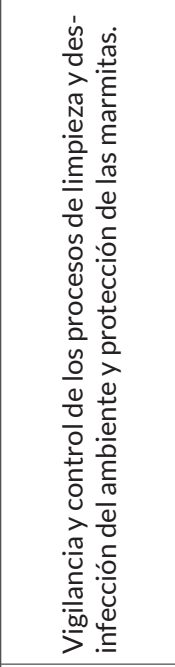 & 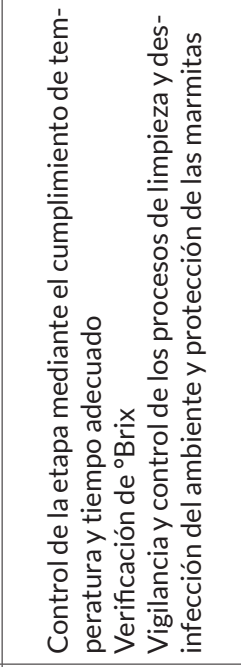 & 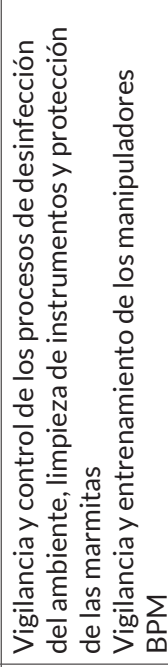 \\
\hline 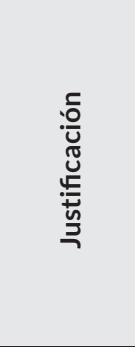 & & 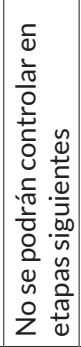 & 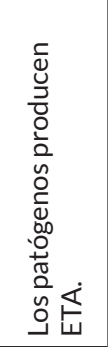 & 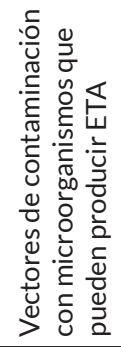 & & 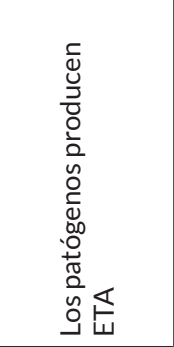 & 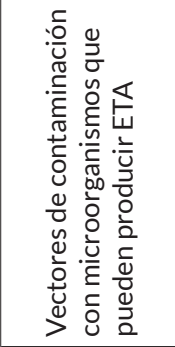 & 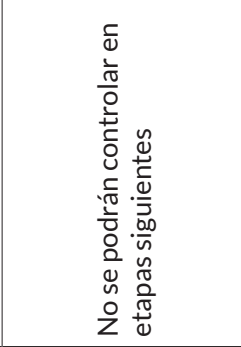 & 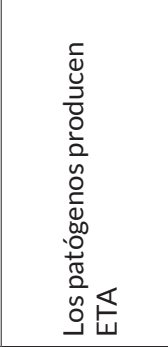 \\
\hline 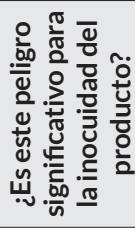 & z & is & is & is & ż & is & $i n z$ & is & $i \bar{s}$ \\
\hline 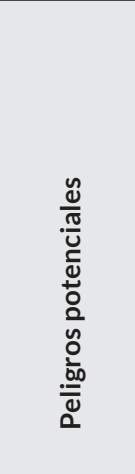 & 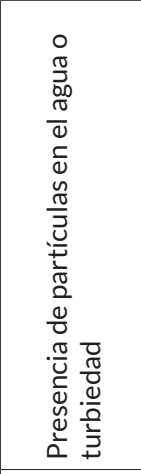 & 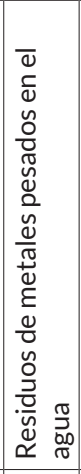 & 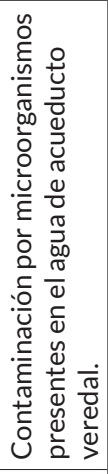 & 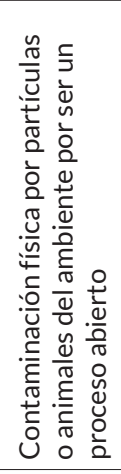 & 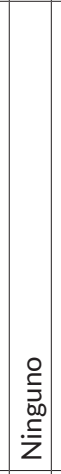 & 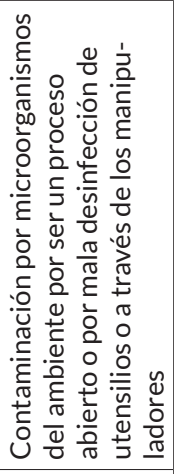 & 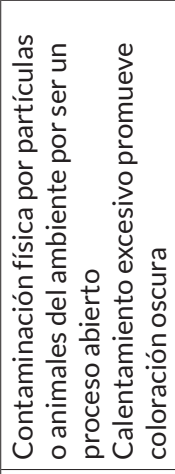 & 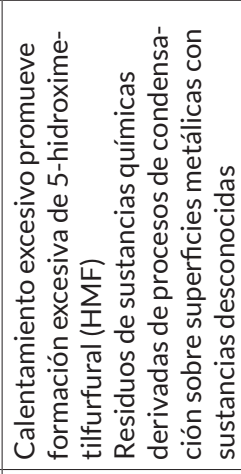 & 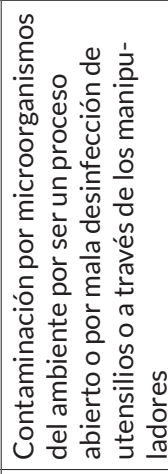 \\
\hline & $\frac{8}{\frac{0}{4}}$ & 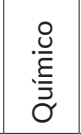 & $\begin{array}{l}\frac{0}{\circ 0} \\
\frac{0}{\circ} \\
\frac{0}{0}\end{array}$ & $\frac{8}{\frac{0}{4}}$ & 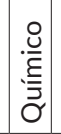 & $\begin{array}{l}\frac{0}{\circ 00} \\
\frac{.0}{0} \\
\frac{0}{0}\end{array}$ & $\frac{8}{\frac{0}{4}}$ & 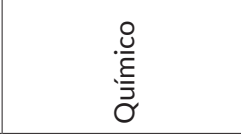 & 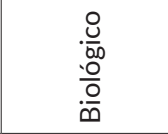 \\
\hline 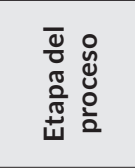 & & 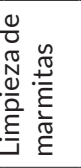 & & & & & & 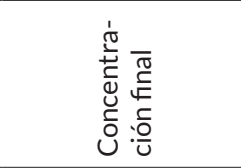 & \\
\hline
\end{tabular}




\begin{tabular}{|c|c|c|c|c|c|c|c|c|}
\hline 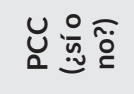 & \multicolumn{3}{|c|}{ is } & \multicolumn{3}{|c|}{ in } & \multicolumn{2}{|l|}{ is } \\
\hline 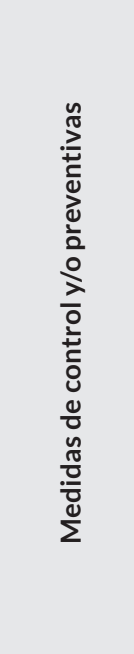 & 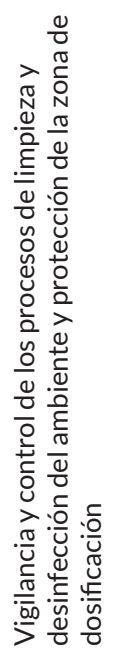 & 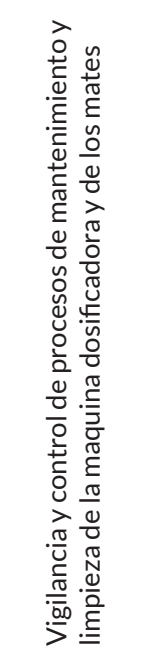 & 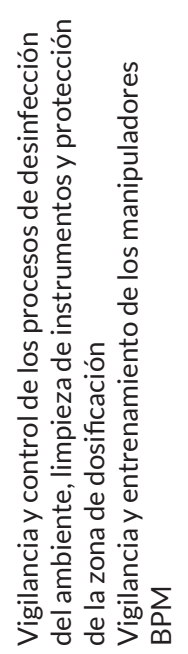 & 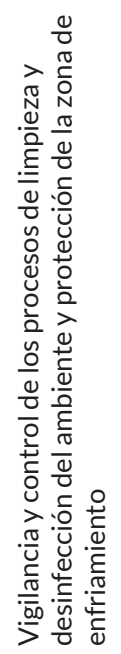 & & 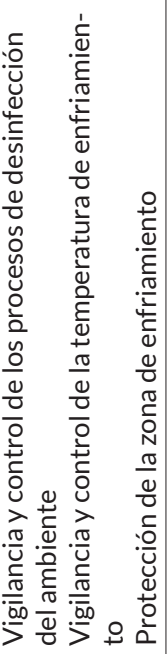 & 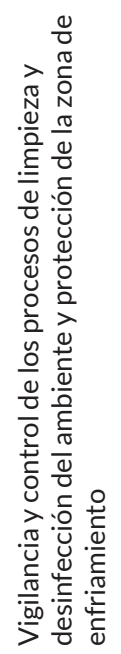 & \\
\hline 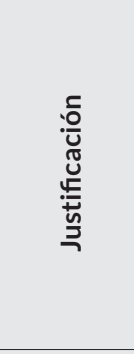 & 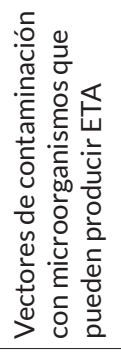 & 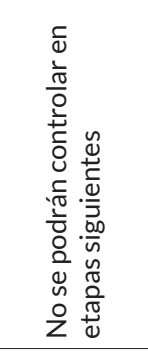 & 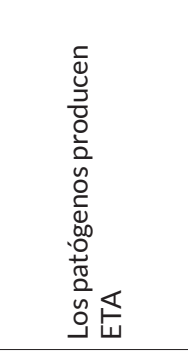 & 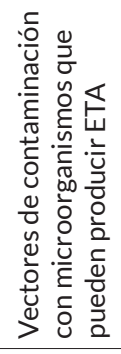 & & 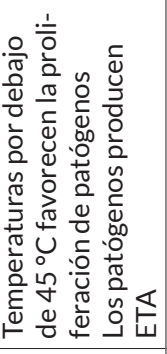 & 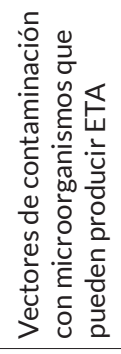 & \\
\hline 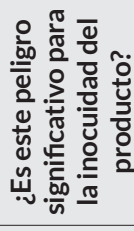 & is & is & is & is & Zे & is & is & zo \\
\hline 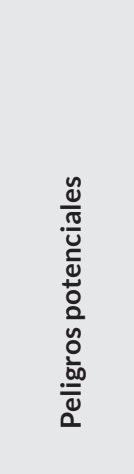 & 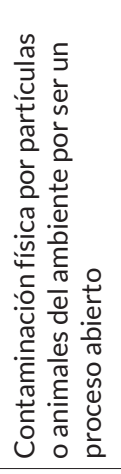 & 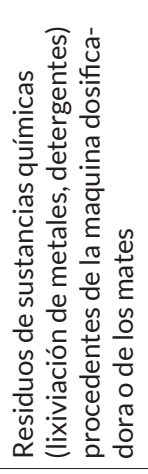 & 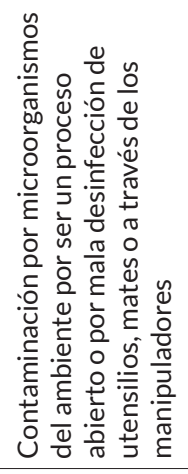 & 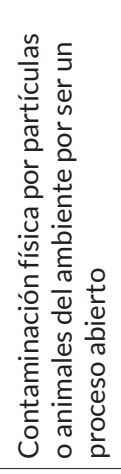 & 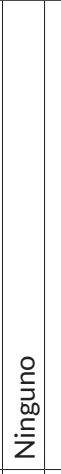 & 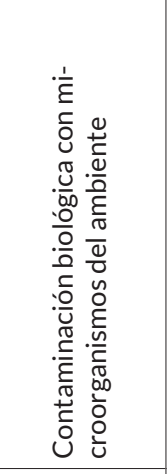 & 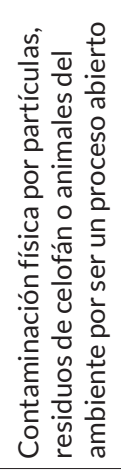 & 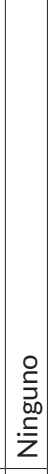 \\
\hline & $\frac{8}{\frac{0}{4}}$ & 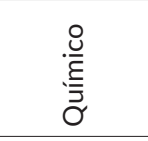 & $\begin{array}{l}\stackrel{0}{\frac{0}{00}} \\
\frac{.0}{\circ} \\
\frac{0}{0}\end{array}$ & $\frac{8}{\frac{0}{4}}$ & 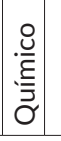 & $\begin{array}{l}\stackrel{0}{\circ 0} \\
\frac{0}{0} \\
\frac{0}{0} \\
\end{array}$ & $\frac{0}{\frac{0}{4}}$ & 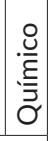 \\
\hline 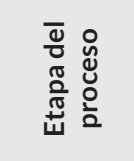 & & $\begin{array}{l}\stackrel{\breve{v}}{\bar{n}} \\
\stackrel{8}{\circ}\end{array}$ & & & 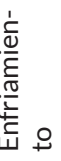 & & 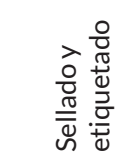 & \\
\hline
\end{tabular}




\begin{tabular}{|c|c|c|c|}
\hline 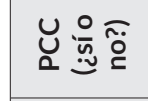 & is & & is \\
\hline 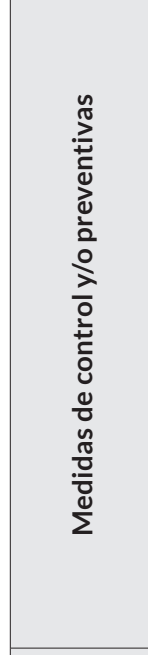 & 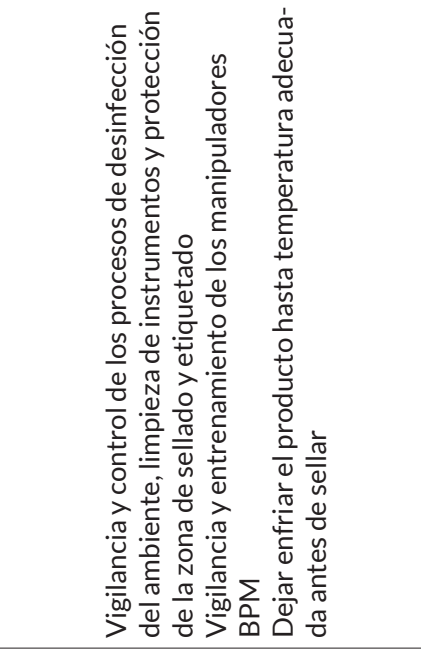 & & 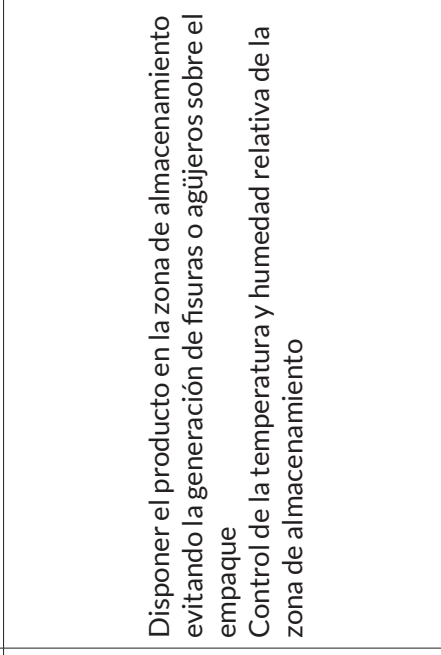 \\
\hline 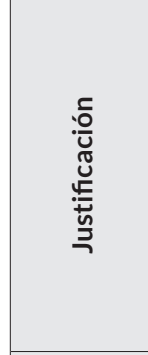 & 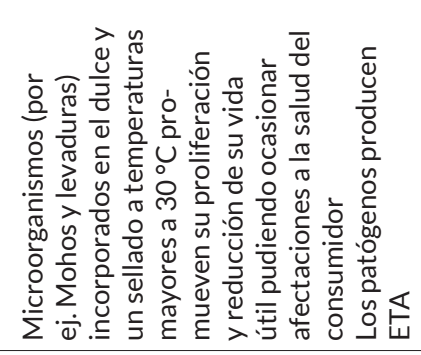 & & 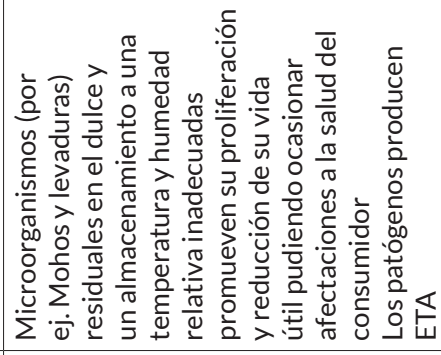 \\
\hline 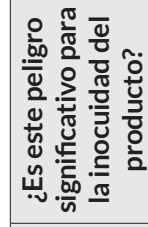 & is & zे zे & $i \bar{s}$ \\
\hline \multirow[t]{2}{*}{ 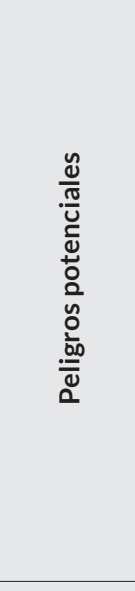 } & 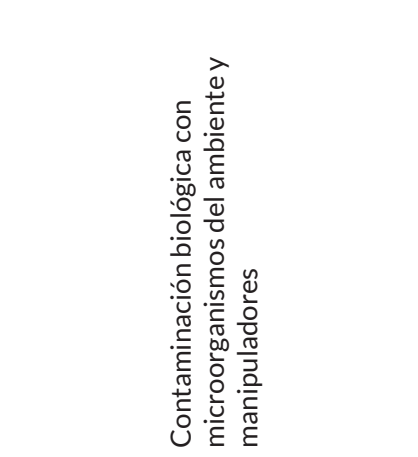 & 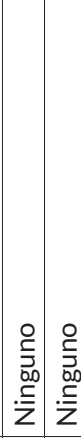 & 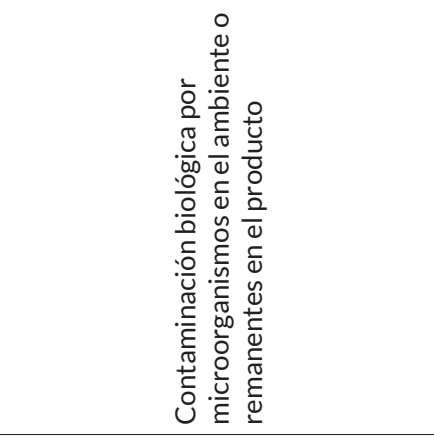 \\
\hline & $\begin{array}{l}\frac{0}{\circ .0} \\
\frac{.0}{\circ} \\
\frac{0}{0}\end{array}$ & 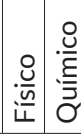 & $\begin{array}{l}\frac{0}{\circ .0} \\
\frac{.0}{\circ} \\
\frac{0}{0}\end{array}$ \\
\hline 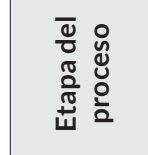 & 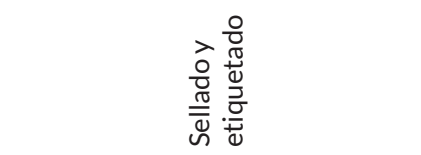 & & 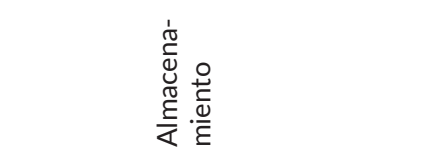 \\
\hline
\end{tabular}




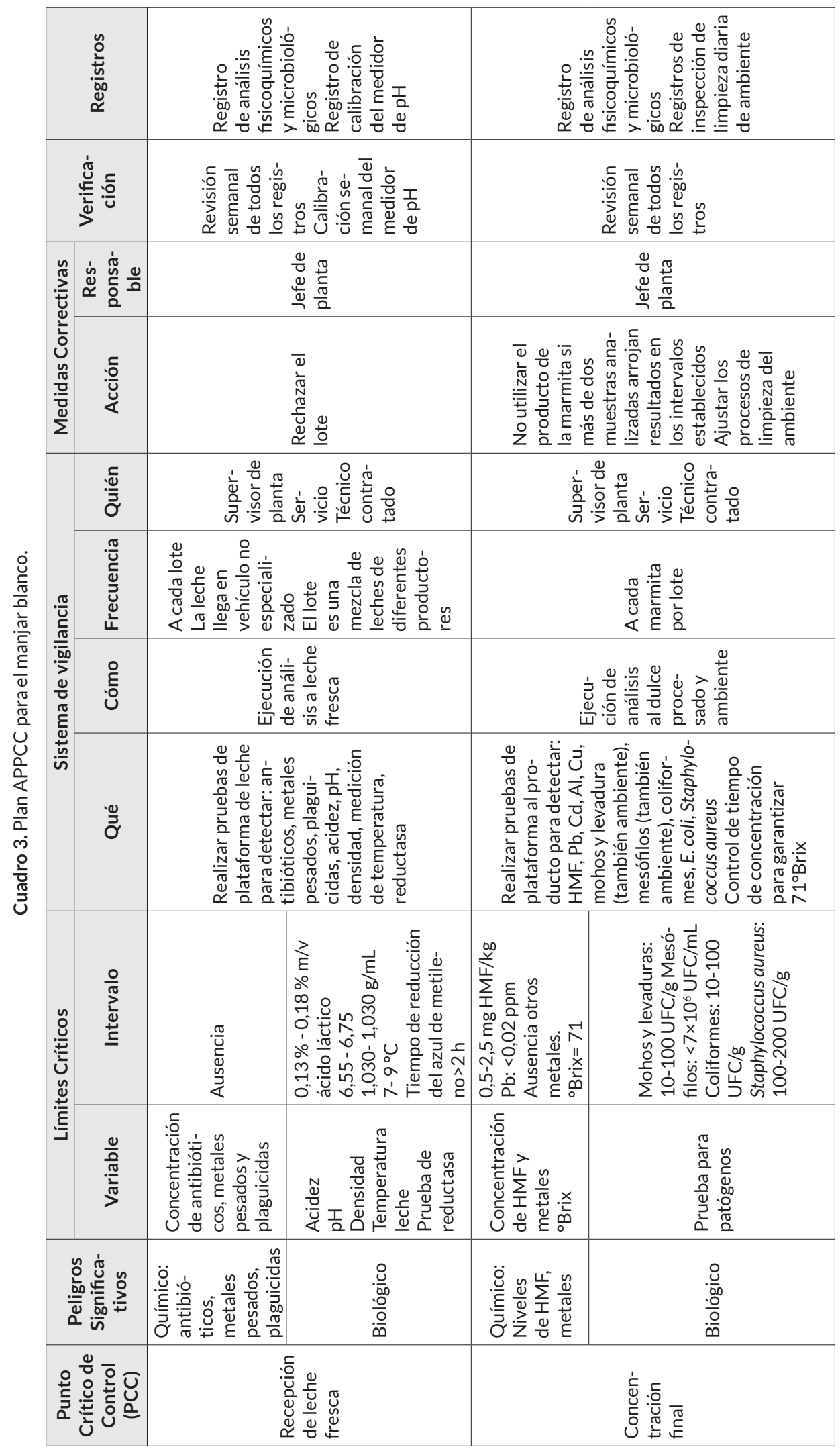




\begin{tabular}{|c|c|c|c|c|}
\hline \multirow{2}{*}{\multicolumn{2}{|c|}{ 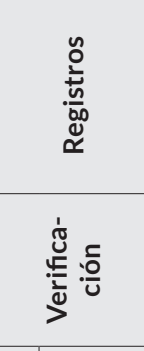 }} & \multicolumn{2}{|c|}{ 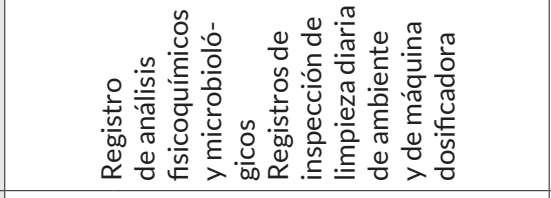 } & 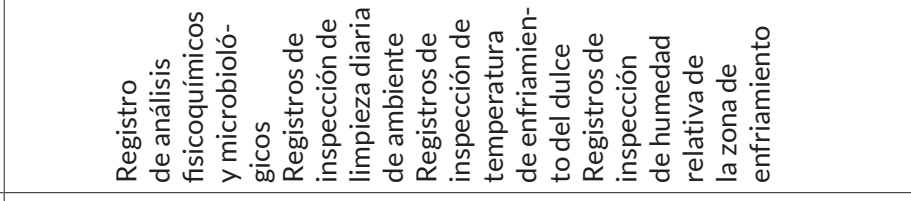 \\
\hline & & & 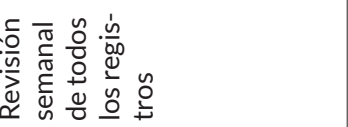 & 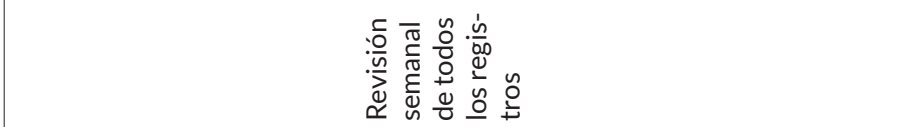 \\
\hline \multirow{2}{*}{ 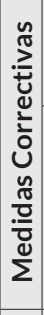 } & \multirow{2}{*}{ 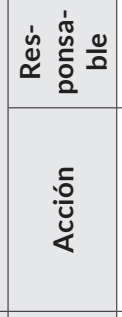 } & \multicolumn{2}{|r|}{$\begin{array}{l}\stackrel{\frac{\pi}{0}}{\frac{\pi}{L}} \\
\stackrel{\frac{\pi}{2}}{\frac{\pi}{2}}\end{array}$} & $\begin{array}{l}\frac{\pi}{0} \frac{\pi}{\frac{\pi}{\pi}} \\
\stackrel{\frac{\pi}{2}}{\frac{\pi}{2}}\end{array}$ \\
\hline & & \multicolumn{2}{|c|}{ 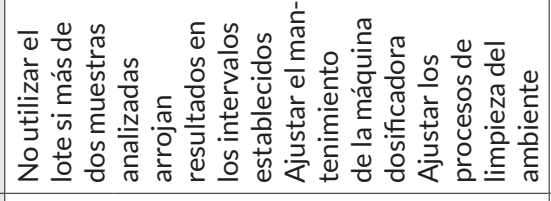 } & 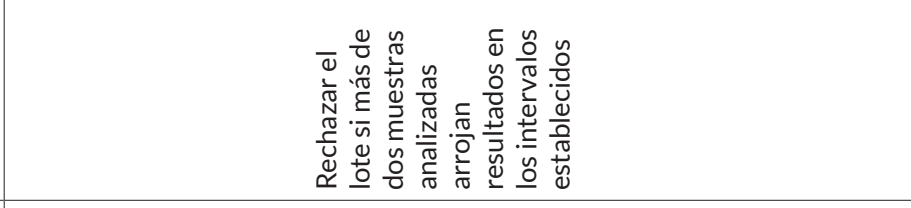 \\
\hline \multirow{4}{*}{ 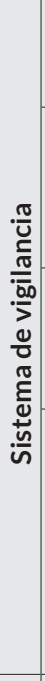 } & 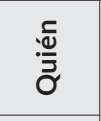 & \multicolumn{2}{|c|}{ 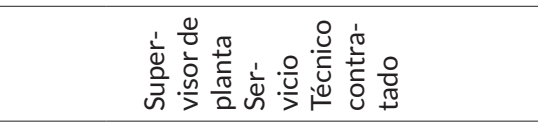 } & 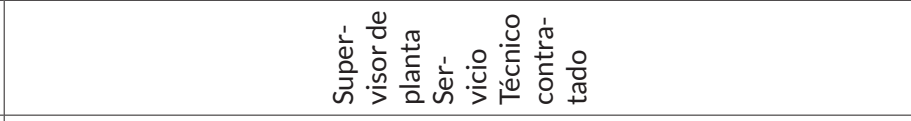 \\
\hline & 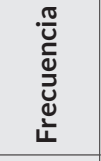 & & $\begin{array}{l}\frac{0}{0} \\
\frac{0}{\pi} \\
\frac{\pi}{0} \\
4\end{array}$ & $\begin{array}{l}\frac{0}{0} \\
\frac{\pi}{0} \\
\frac{\pi}{4} \\
4\end{array}$ \\
\hline & ؛ें & & 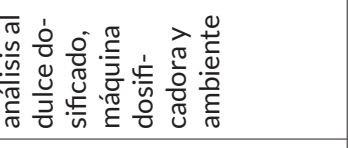 & 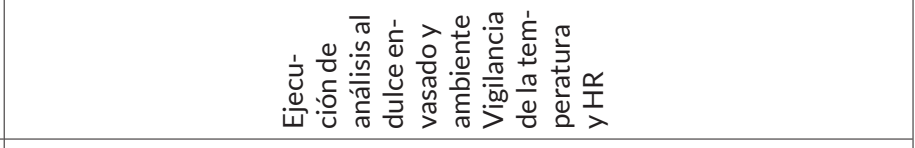 \\
\hline & $\stackrel{\mathscr{0}}{\widetilde{\sigma}}$ & & 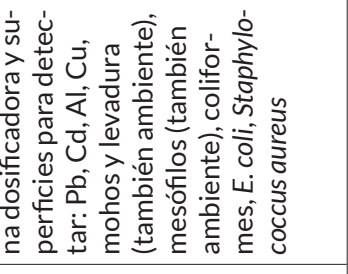 & 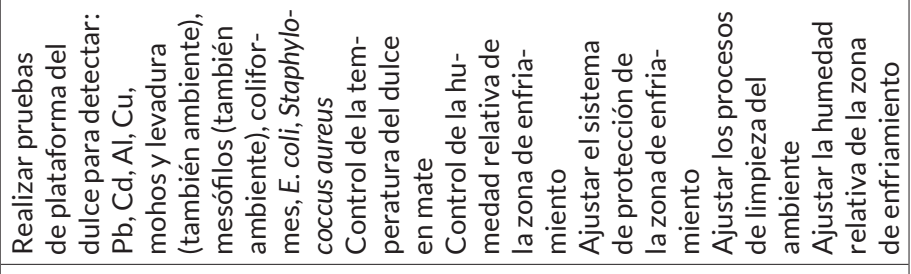 \\
\hline \multirow{2}{*}{ 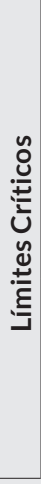 } & $\begin{array}{l}\frac{0}{\sqrt{n}} \\
\frac{2}{0} \\
\stackrel{ \pm}{\leq}\end{array}$ & 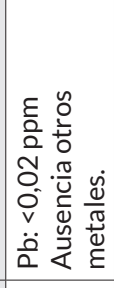 & 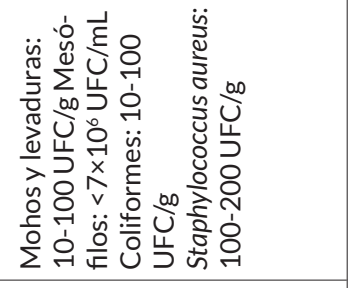 & 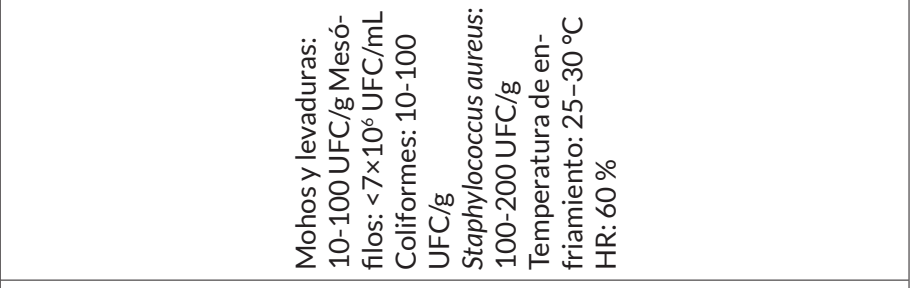 \\
\hline & $\frac{\frac{0}{2}}{\frac{\sqrt[0]{\frac{\pi}{2}}}{>}}$ & 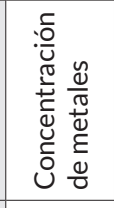 & 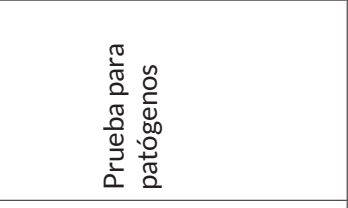 & 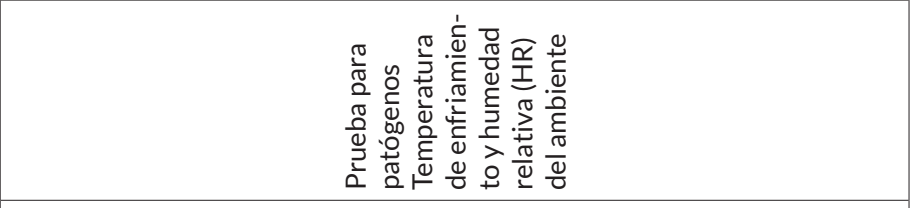 \\
\hline \multicolumn{2}{|c|}{ 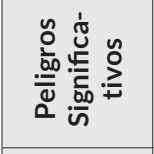 } & 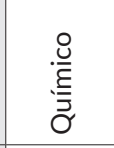 & $\begin{array}{l}\frac{0}{0.0} \\
\frac{0}{0} \\
\frac{0}{0}\end{array}$ & $\begin{array}{l}\frac{8}{60} \\
\frac{.0}{0} \\
\frac{0}{0}\end{array}$ \\
\hline \multicolumn{2}{|c|}{ 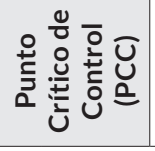 } & \multicolumn{2}{|r|}{ 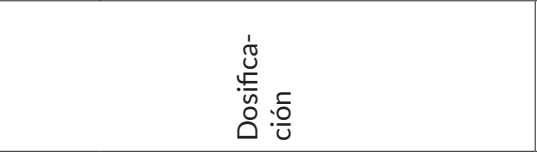 } & 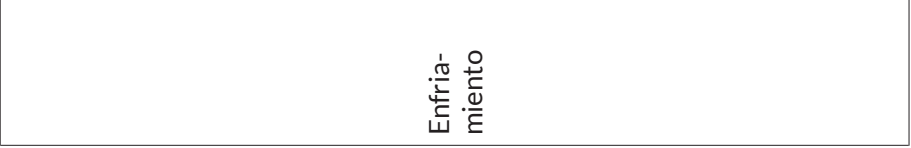 \\
\hline
\end{tabular}




\begin{tabular}{|c|c|c|}
\hline 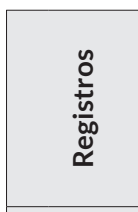 & 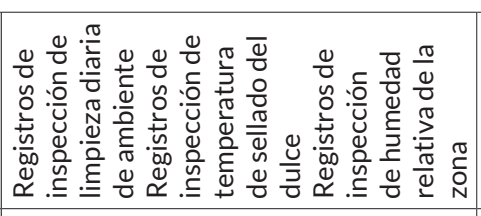 & 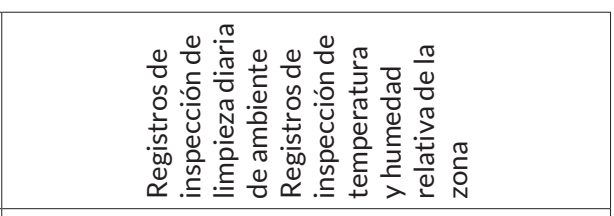 \\
\hline 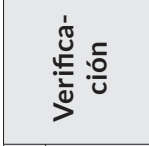 & 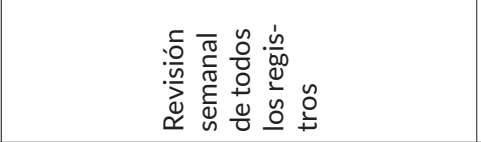 & 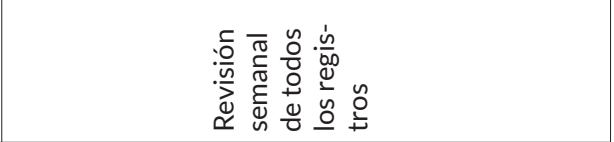 \\
\hline 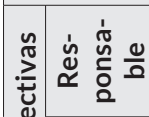 & 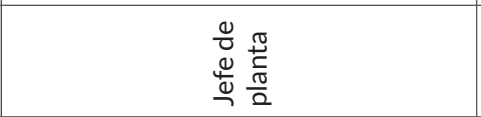 & 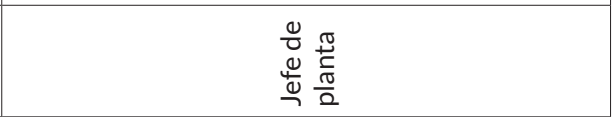 \\
\hline 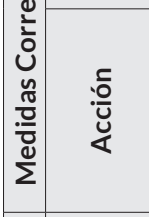 & 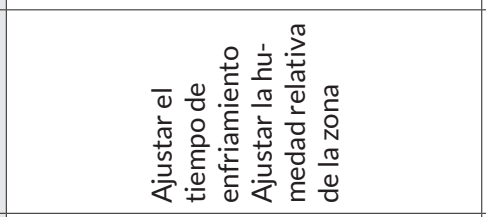 & 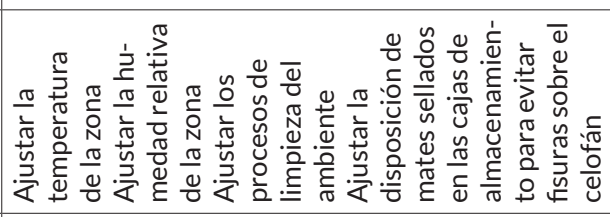 \\
\hline$\stackrel{\bar{\omega}}{\bar{\sigma}}$ & 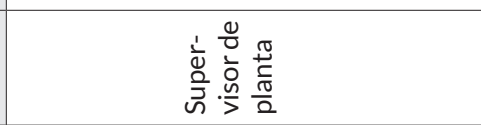 & 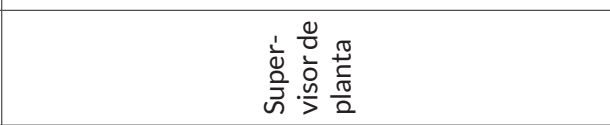 \\
\hline 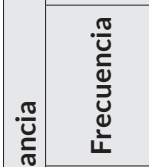 & $\begin{array}{l}\frac{0}{0} \\
\frac{\pi}{\pi} \\
\frac{\pi}{0} \\
<\end{array}$ & $\begin{array}{l}\frac{\pi}{0} \\
\frac{0}{\pi} \\
\frac{\pi}{\pi} \\
\mathbb{4}\end{array}$ \\
\hline 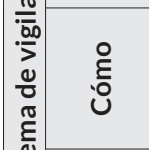 & 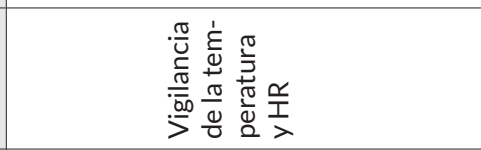 & 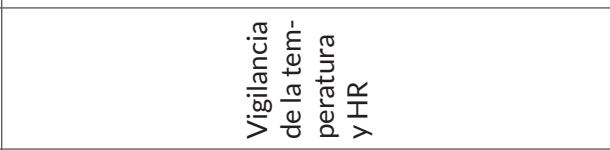 \\
\hline 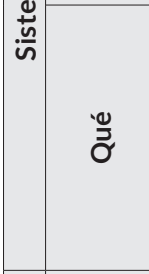 & 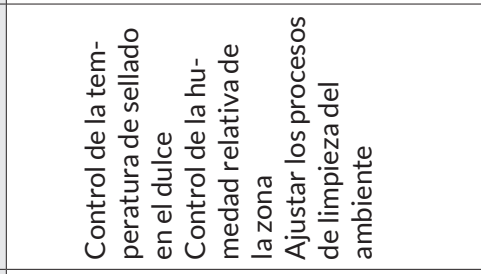 & 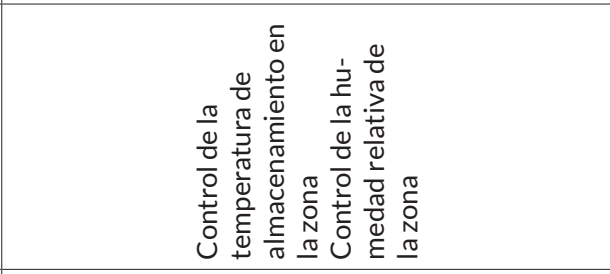 \\
\hline 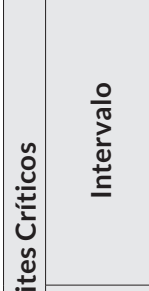 & 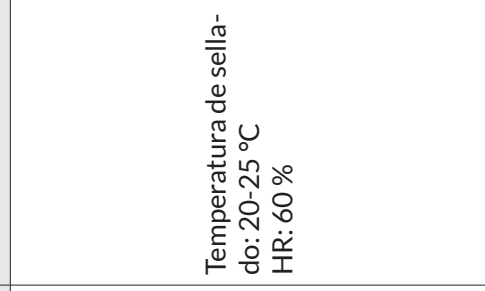 & 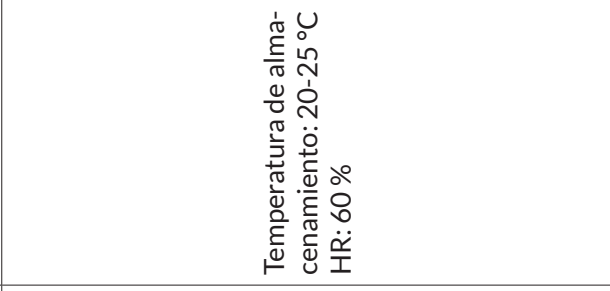 \\
\hline 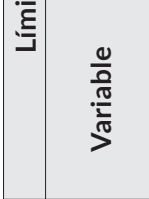 & 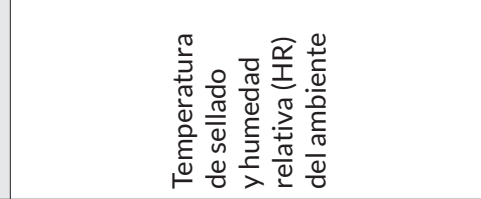 & 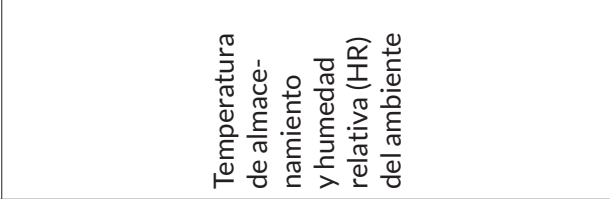 \\
\hline 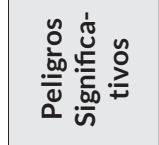 & $\begin{array}{l}\frac{8}{\circ 0} \\
\frac{.0}{\circ} \\
\frac{0}{00}\end{array}$ & $\frac{\stackrel{0}{\circ}}{\frac{.0}{\circ}}$ \\
\hline 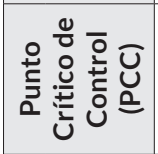 & 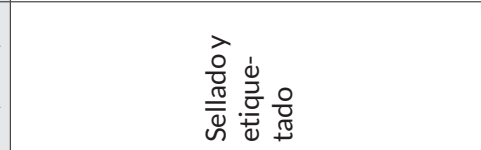 & 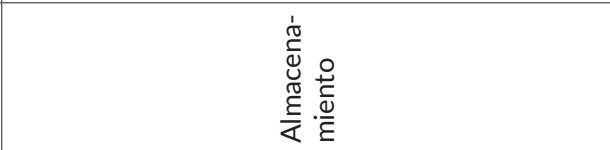 \\
\hline
\end{tabular}


Igualmente, en la etapa de concentración final, una excesiva formación de 5-hidroximetilfurfural (HMF) y su derivado (5-sulfoximetilfurfural, SMF) por efecto de un calentamiento prolongado (dosis de $200 \mathrm{mg} / \mathrm{kg}$ o 25 $\mathrm{mg} / \mathrm{kg}$, respectivamente, en estudios in vivo), se asocian con daño en el ADN, formación de inhibidores del crecimiento y actividades citotóxicas, genotóxicas, mutagénicas y cancerígenas (Shapla et al., 2018). Por ello, es necesario controlar en esta etapa los niveles de HMF, ${ }^{\circ}$ Brix, concentración de metales pesados y carga de microorganismos procedentes del ambiente, superficies o manipuladores. Niveles no deseados representan riesgo de proliferación en posteriores etapas y, por lo tanto, disminución del tiempo de vida útil del producto y, adicionalmente, un color más oscuro que el deseado.

En la etapa de dosificación se debe controlar ausencia de metales pesados lixiviados de la máquina dosificadora y niveles inaceptables de microorganismos patógenos asociados con el ambiente y superficies.

Por su parte, la etapa de enfriamiento promueve la proliferación rápida de mohos y levaduras, principalmente, si no se garantiza el enfriamiento del producto bajo una baja humedad relativa, un ambiente protegido y/o libre de contaminación biológica (Greco et al., 2017). La etapa de sellado y etiquetado también representa un punto crítico de control, que incluye a la temperatura de sellado y la humedad relativa del ambiente, debido a que diferencias entre el contenido de humedad residual en el producto (a causa de un sellado a altas temperaturas) y el del ambiente promoverían durante el almacenamiento una transferencia de agua desde el medio hacia la parte interna del producto hasta alcanzar un equilibrio, al tiempo que proporciona un ambiente ideal para la proliferación de mohos y levaduras.

Finalmente, como parte del procesamiento del dulce, es necesario controlar la etapa de almacenamiento a través de la vigilancia de la temperatura del mismo y de la humedad relativa del ambiente. Similar a las etapas de enfriamiento y sellado, temperaturas superiores a la del ambiente, favorecerían el desarrollo de mohos y levaduras y proliferación a niveles inaceptables para el consumidor en menos de 90 días.

El plan APPCC se debe verificar para garantizar su efectiva operatividad; esta fase deberá incluir la revisión integral del plan, la aceptación de los PCC y límites críticos, la revisión de los registros de las correcciones, desviaciones o gráficos de control. Así mismo, los registros se deben archivar y el equipo APPCC se debe actualizar en todo lo relacionado al marco normativo nacional de interés.

\section{CONCLUSIONES}

El análisis de peligros para el proceso de elaboración de manjar blanco, a partir de la observación, estableció que los peligros químicos (residuos de antibióticos, pesticidas, metales, HMF) y biológicos (mesófilos y mohos y levaduras entre otros) son los que principalmente afectan la inocuidad del producto final. Estos hallazgos se deben contrastar con ensayos químicos y microbiológicos. El árbol de decisión permitió identificar que varios peligros se pueden controlar a través de una misma medida de control y más de una etapa del procesamiento puede estar involucrada en el control de un determinado peligro. Las etapas de: recepción de leche fresca, concentración final, dosificación, enfriamiento, sellado y etiquetado, y almacenamiento se establecieron como PCC del proceso de fabricación. A partir del análisis de peligros (Cuadro 2) y el control del APPCC (Cuadro 3), el equipo APPCC de la empresa puede iniciar su implementación y verificación previo ajuste y cumplimiento de BPM y POLD (perfil sanitario inicial $70 \%$ ). Esto a corto plazo favorecería la vida útil del producto y los índices de productividad de la empresa. 


\section{AGRADECIMIENTOS}

A la gerencia y al personal operativo de la empresa donde se llevó a cabo este estudio el cual se desarrolló a través del Convenio de Cooperación 6-81.2/013 de 2018 financiado por el Sistema General de Regalías 2013, proyecto ID-3848 de la Vicerrectoría de Investigaciones de la Universidad del Cauca, y en el marco del proyecto 04A-2018-44 del Programa InnovAcción Cauca.

\section{REFERENCIAS}

BIRHANU, WASSIE; HAGOS, YOHANNES; BASSAZIN, GASHAW; MITKU, FENTAHUN. A review on hazard analysis critical control point in milk and milk products. World Journal of Dairy \& Food Sciences, v. 12, n. 1, 2017, p. 52-65. 10.5829/idosi.wjdfs.2017.52.65

CANCINO-PADILLA, NATHALY; FELLENBERG, MARÍA-ANGÉLICA; FRANCO, WENDY; IBAÑEZ, RODRIGO A.; VARGAS-BELLO-PÉREZ, EINAR. Foodborne bacteria in dairy products: Detection by molecular techniques. Ciencia e Investigación Agraria, v. 44, n. 3, 2017, p. 215-229. https://doi.org/10.7764/rcia.v44i3.1811

CHEN, A.J.; HUBKA, V.; FRISVADC, J.C.; VISAGIE, C.M.; HOUBRAKENM, J.; MEIJER, M.; VARGA, J.; DEMIREL, R.; JURJEVIC, Z.; KUBATOVA, A.; SKLENAR, F.; ZHOU, Y.G.; SAMSON, R.A. Polyphasic taxonomy of Aspergillus section Aspergillus (formerly Eurotium), and its occurrence in indoor environments and food. Studies in Mycology, v. 88, 2017, p. 37-135. https://doi.org/10.1016/j.simyco.2017.07.001

ITALIA. COMISIÓN DEL CODEX ALIMENTARIUS. Directrices para la aplicación del Sistema de Análisis de Peligros y de Puntos Críticos de Control (HACCP). 1997. http://www.fao.org/3/y1579s/y1579s03.htm [consultado septiembre 2 de 2019].

DÍAZ, OMAR; BETANCOURT-AGUILAR, CARMEN-ROSA. Los pesticidas: clasificación, necesidad de un manejo integrado y alternativas para reducir su consumo indebido: una revisión. Revista Científica Agroecosistemas, v. 6, n. 2, 2018, p. 14-30.

DÍAZ-ARANGO, FÉLIX-OCTAVIO; JIMÉNEZ, JHON-MAURICIO; MARTÍNEZ, MARÍA-MARCELA. Diseño de estrategias para mejorar la competitividad de la industria láctea. Revista de ingeniería, v. 43, 2015, p. 40. http://dx.doi.org/10.16924\%2Friua.v0i43.865

FERRÃO, JORGE; BELL, VICTORIA; CHABITE, I.T.; FERNANDES, T.H. Mycotoxins, food and health. Journal Nutrition Health Food Science, v. 5, n. 7, 2017, p. 1-10. https://doi.org/10.15226/jnhfs.2017.001118

GARNIER, LUCILLE; VALENCE, FLORENCE; MOUNIER, JÉRÖME. Diversity and control of spoilage fungi in dairy products: an update. Microorganisms, v. , n. 3, 2017, p. 42. https://doi.org/10.3390/microorganisms5030042

GRECO, MARIANA; PARDO, ALEJANDRO; POSE, GRACIELA; PATRIARCA, ANDREA. Effect of water activity and temperature on the growth of eurotium species isolated from animal feeds. Revista lberoamericana de Micología, v. 35, n. 1, 2017, p. 39-48. HTTPS://10.1016/J.riam.2017.04.002

HIROSHI, HÉLIO; GUEMRA, SAMUEL; BOSSO, ALESSANDRA; DE PÁDUA, ÉRIKA; ITO M., LUIS-RODRIGO. Reducción de proteínas y glucosa por reacción de maillard en leche con lactosa hidrolisada. Revista Chilena de Nutrición, v. 47, n. 1, 2020, p. 14-21. https://dx.doi.org/10.4067/s0717-75182020000100014

INSTITUTO COLOMBIANO DE NORMAS TÉCNICAS Y CERTIFICACIÓN (ICONTEC). Norma Técnica Colombiana NTC 3757: Arequipe o dulce de leche y manjar blanco. Bogotá (Colombia): 2008, 15 p.

INSTITUTO COLOMBIANO DE NORMAS TÉCNICAS Y CERTIFICACIÓN INTERNACIONAL. Análisis de los impactos de la implementación de las normas técnicas y de las certificaciones de sistemas de gestión y de producto. Casos de estudio del sector agroalimentario. Bogotá (Colombia): 2018, 126 p. 
KAKIMOV, AITBEK; MURATBAYEV, ALIBEK; ZHARYKBASOVA, KLARA; ZHARYKBASOV, YERLAN; KASSYMOV, SAMAT; ZHUMADILOVA, GULMIRA; JUMAZHANOVA, MADINA; UTEGENOVA, ASIYA. Developing haccp plan for a fermented milk drink with encapsulated biologically active supplements. EurAsian Journal of BioSciences, v. 14, n. 1, 2020, p. 889-895.

MENESES, RUTH-MERCEDES; ESTRADA, DIANA-MARCELA; CHANTRÉ, CARLOS-ANDRÉS; LÓPEZ, FREDYJAVIER. Caracterización en la cadena informal de la leche cruda en el municipio de Popayán. Biotecnoloía en el Sector Agropecuario y Agroindustrial, v. 13, n. 2, 2015, p. 130-139. https://doi.org/10.18684/BSAA(13)130-139

COLOMBIA. MINISTERIO DE SALUD. Decreto 3075. 1997. https://www.minsalud.gov.co/Normatividad Nuevo/DECRETO 3075 DE 1997.pdf. [consultado septiembre 2 de 2019].

MOTTA-DELGADO, PABLO-ANDRÉS; RIVERA, MALHORY-STEFANNY; DUQUE, JAIRO-ANDRÉS; GUEVARA, FABIO-ANDRÉS. Factores inherentes a la calidad de la leche en la agroindustria alimentaria. Revista Colombiana de Ciencia Animal, v. 6, n. 1, 2014, p. 223-242. https://doi.org/10.24188/recia.v6.n1.2014.265

NAJAH, ZULFATUN; PUTRI, NIA. A review of hazard analysis and critical control points implementation in amplang processing. Food Scientech Journal, v. 1, n. 1, 2019, p. 54-64. https://doi.org/10.33512/fsj.v1i1.6187

NOVOA, DIEGO; RAMÍREZ-NAVAS, JUAN-SEBASTIÁN. Manjar Blanco del Valle: un dulce de leche típico colombiano. Tecnología Láctea Latinoamericana, v. 69, 2012, p. 48-52.

ORGANISMO INTERNACIONAL REGIONAL DE SANIDAD AGROPECUARIA. Manual de Buenas Prácticas de Manufactura para productos acuícolas y pesqueros. San Salvador (El Salvador): 2017, 42 p.

ORGANIZACIÓN MUNDIAL DE LA SALUD (OMS). Inocuidad de los alimentos. 2019. https://www.who.int/es/ news-room/fact-sheets/detail/food-safety [consultado septiembre 2 de 2019]

ORTEGA-IBARRA, EDÚ; HERNÁNDEZ-JIMÉNEZ, ANDREA. Seguridad alimentaria y nutricional, higiene e inocuidad: fundamentos Microbiológicos. Revista UServa, v. 3, 2017, p. 44-51.

RAMÍREZ-NAVAS, J.; CALLEJAS, G.; QUICENO, C.; VALENCIA, Y. Preferencia y aceptación de dos dulces de leche típicos colombianos: resultados de una encuesta a consumidores. UGCiencia, v. 21, 2015, p. 9-15.

REMÓN-DÍAZ, DYANIS; GONZÁLEZ-REYES, DAYAIMI; MARTÍNEZ-VASALLO, AILIN. Evaluación de la calidad higiénico-sanitaria de la leche cruda por métodos de flujo citométrico. Revista de Salud Animal, v. 41, n. 1, 2019, p. 1-9.

RESTREPO, FERNANDO; RODRÍGUEZ, HOLMES; ANGULO, JOAQUÍN. Consumo de lácteos en población universitaria de la ciudad de Medellín. Revista Chilena de Nutricion, v. 42, n. 1, 2015, p. 35-40. http://dx.doi.org/10.4067/S0717-75182015000100004

RODRÍGUEZ, ANALÍA; LEMA, PATRICIA; BESSIO, MARÍA-INÉS; MOYNA, GUILLERMO; PANIZZOLO, LUISALBERTO; FERREIRA, FERNANDO. Isolation and characterization of melanoidins from dulce de leche, a confectionary dairy product. Molecules, v. 24, n. 22, 2019, p. 4163. https://doi.org/10.3390/molecules24224163

RUÍZ-ROJAS, JORGE-LUIS; GUTIÉRREZ-TOLENTINO, REY; ORANTES-ZEBADUA, MIGUEL A.; MANZURCRUZ, ALBERTO. Contaminación por micotoxinas de la leche y derivados lácteos. Que hacer Científico en Chiapas, v. 12, n. 1, 2017, p. 90-103.

SHAPLA, UMMAY-MAHFUZA; SOLAYMAN, M.D.; ALAM, NADIA; KHALIL, M.D. IBRAHIM; GAN, SIEW-HUA. 5-Hydroxymethylfurfural (HMF) levels in honey and other food products: effects on bees and human health. Chemistry Central Journal, v. 12, n. 1, 2018, p. 1-18.

http://dx.doi.org/10.1186/s13065-018-0408-3

STEPHANI, RODRIGO; FRANCISQUINI, JÚLIA; TULER-PERRONE, ÍTALO; FERNANDES-DE CARVALHO, ANTONIO; CAPPA-DE OLIVEIRA, LUIZ-FERNANDO. Dulce de leche-chemistry and processing technology. En: JAVED KHALID; Milk production, processing and marketing. London (United Kingdom): IntechOpen, 2019, $18 \mathrm{p}$.

http://dx.doi.org/10.5772/intechopen.82677 
TOMAR, OKTAY; AKARCA, GÖKHAN. Critical control points and food pathogen presence in dairy plants from Turkey. Food Science and Technology, v. 39, n. 2, 2019, p. 444-450. https://doi.org/10.1590/fst.29717

VAN-ASSELT, ESTHER D.; VAN DER FELS-KLERX, H.J.; MARVIN, H.J.P.; VAN BOKHORST-VAN DE VEEN, H.; NIEROP-GROOT, M. Overview of food safety hazards in the european dairy supply chain. Comprehensive Reviews in Food Science and Food Safety, v. 16, 2017, p. 59-75. https://doi.org/10.1111/1541-4337.12245 